\title{
Signaling for Attention: Mobility and Student Performance in United Way's Promise Neighborhoods
}

\author{
Neil Cronkrite, Department of Economics, University of Oregon \\ Ian O'Gorman, Department of Economics, University of Oregon
}

\begin{abstract}
From a middle school student's perspective, the worst part about transferring schools is the need to make new friends. But is that the only negative impact of mobility on students? In this paper, we use a fixed effects linear least-squares statistical regression model to explore the relationship between student academic performance and student mobility in the Bethel School District in Eugene, Oregon. Our client, United Way of Lane County, has struggled with student mobility as the organization refines its new Promise Neighborhoods project, aimed at distressed neighborhoods in Lane County. Student mobility may limit United Way's ability to improve the educational and developmental outcomes of students. We use voter registration data to estimate total mobility in Lane County and in the Promise Neighborhoods. We also use Bethel School District student transfer codes and statewide state test scores as data. Due to the structure of our data, we cannot draw a definitive conclusion regarding the direction of causality between mobility and learning. However, we can say with confidence that, at a minimum, there is a significant relationship between disruption to learning and high levels of mobility - a good starting point for United Way as they continue to explore mobility and refine its Promise Neighborhoods project.
\end{abstract}

\section{Introduction}

United Way is a national non-profit organization that collects and allocates donations to benefit communities in need. Lane County's United Way headquarters is in Eugene, Oregon; this office focuses on serving Lane County. United Way has three primary goals centered on education, income, and health. These goals include preparing children to succeed in school and life, moving families from poverty to financial stability, and ensuring people have access to basic health care. United Way's ability to achieve these goals depends on its ability to understand, prioritize, and best respond to the needs of Lane County residents.

United Way's positive impacts on Lane County residents are a function of its projects and programs. The Promise Neighborhoods, a new project developed by United Way, will develop a continuum of "cradle through college and career solutions" to improve the educational and developmental outcomes of children living in Lane County's most distressed areas (United Way, 2010). Inspired by the success of the Harlem Children's Zone, the Promise Neighborhoods project aims at providing a comprehensive support system for families and children at risk. 
Student mobility - a student's physical change of address - is an important topic in education and in United Way's research agenda. Holly Mar Conte, United Way of Lane County's Associate Director of Education, explained that student mobility may become a significant topic on United Way's agenda as they continue to develop a formal strategy for the Promise Neighborhoods (Mar Conte, 2011). Mobility has been a discussion topic in United Way meetings, but little is known about its effect on students or the surrounding community.

Mobility raises two primary concerns for United Way and its goals in the Promise Neighborhoods. First, mobility poses financial impacts. United Way has finite financial resources, and they must make decisions on how best to effectively allocate their money in order to produce efficient and effective programs that generate positive outcomes. The movement of students in and out of the Promise Neighborhoods could threaten to reduce the effectiveness of a dollar spent in the Promise Neighborhoods relative to a dollar spent in a less mobile area. Second, mobility may affect student performance. There is evidence that student mobility has a negative effect on school performance (Beatty, 2010). If there is a high mobility rate in the Promise Neighborhoods, then students who are more mobile will be less likely to be "ready to learn" - a possible phenomenon and major concern in the Promise Neighborhoods that United Way seeks to address.

Based on these concerns, we investigated three main questions: what are the specific mobility rates - within, between, to, and from - in the Promise Neighborhoods? Should United Way be concerned? What kind of data should United Way collect for future studies? We predict mobility has a significant effect on student test scores. In the next section, we will outline our background research on the topic.

\section{Background Information}

United Way's Promise Neighborhood is based loosely on the Harlem Children's Zone (HCZ). The project began in the early 1990s, when HCZ organized a wide range of support services for a single block in Harlem, a neighborhood in New York City. The goal was to address typical problems facing poor families: violent crime, chronic health issues, failing schools, and inadequate housing. The single block program eventually expanded to cover a 24-block area. United Way created the Promise Neighborhoods program to mirror the successes of HCZ. The Promise Neighborhoods will focus on two small neighborhoods in the Bethel and Springfield School Districts and will primarily target childhood development and education. The vision is to develop a full continuum of support for children in these areas. Currently, around 82 percent of children in the Promise Neighborhoods entering kindergarten do not meet the early literacy benchmark, determined by United Way as its indicator of "learning readiness" (Mar Conte, 2011). This benchmark includes simple skills such as knowing how to hold a book or recognizing letters of the alphabet.

Specifically, within the district lines of Fairfield and Malabon Elementary schools, which span the Bethel Promise Neighborhood, 92\% and 88\% of kindergarten students are below the benchmark set by United Way (Mar Conte, 2011). Brattain and Maple Elementary Schools in the Springfield Promise Neighborhood have $76 \%$ and $71 \%$ of students under United Way's 
benchmark, respectively (Mar Conte, 2011). We believe these statistics may exhibit sampling error and bias; United Way only surveyed a handful of kindergarteners, resulting in a small sample size. Nonetheless, they are indicators of the poor academic performance common to the Promise Neighborhoods. Figures 1 and 2 show boundary maps of the Promise Neighborhoods. Figure 1 shows the Springfield Promise Neighborhood, and Figure 2 the Bethel Promise Neighborhood.

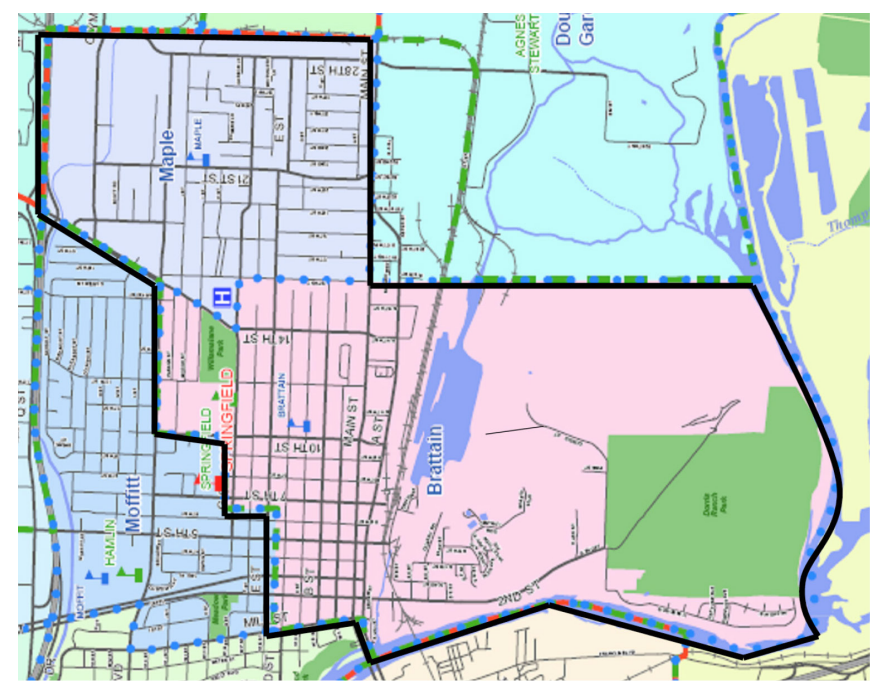

Figure 1. Map of Springfield Promise Neighborhood.

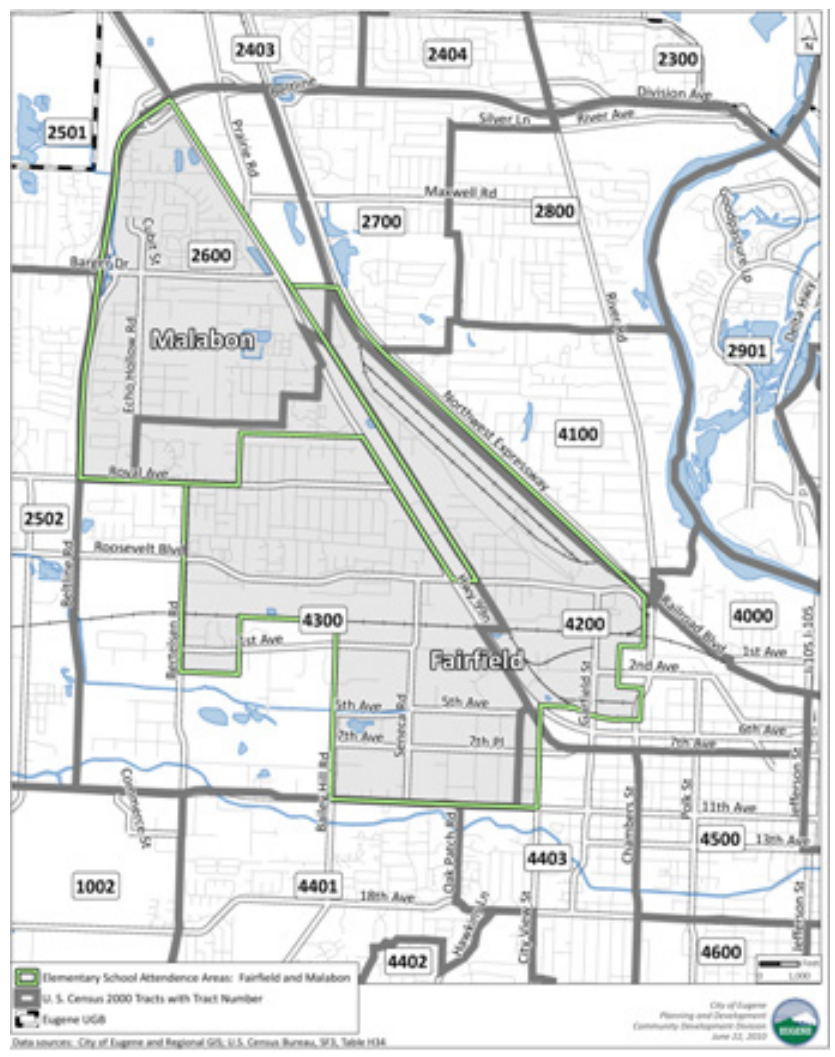

Figure 2. Map of Bethel School District, showing the Bethel Promise Neighborhood. 
Having consulted the current scholarly literature on student mobility and performance, we find that the relationship between student mobility and test performance is somewhat unclear. This may be due to the geographic scope of the various analyses. When studies draw from a national database, the effects of mobility and performance dissipate. That is, the more heterogeneous the sample, the harder it is to isolate the effects of mobility on student performance. For example, at a recent conference on student mobility, Lee and Burkam hypothesized that demographic characteristics of children and their families impact mobility (Lee and Burkam, 2009). They used national data to determine mobility rates by race, socioeconomic status, and gender. Lee and Burkam observed that the effects of mobility seem to be small, and that mobility appears less intrusive as an overall effect when one considers an entire population (Lee and Burkam, 2009). On the other hand, effects of mobility and student performance strengthen within local projects or studies that draw from more a homogeneous sample. For example, the Chicago Longitudinal Study finds that one move costs students about two months' worth of achievement, and that students who move three or more times are five to six months behind their peers (Kerbow, 1996). Since this study is based on data gathered in Chicago, consequences of mobility on student performance are more evident.

When scholars do find statistically significant effects, they conclude that mobility has a negative impact on student performance. Highly mobile children perform worse on academic achievement tests than their peers (Beatty, 2010). Repeated mobility - when a student changes schools more than once in a short time period - has a consistently negative effect and its magnitude increases with the frequency of moves (Beatty, 2010). Reynolds and his colleagues found a significant relationship between mobility and both lower school achievement and dropout rates (Beatty, 2010). Additionally, he finds that both early mobility and mobility during high school have the greatest impact on these measures of student achievement.

Yet the literature is likewise unclear on mobility's relationship to specific academic skills. Many scholars suggest students who move repeatedly often fall further behind those of their peers in reading skills (Smith, Fien, and Paine, 2008). At the same conference on student mobility, Lee and Burkam highlighted research indicating that moving had a lesser effect on mathematics performance than on reading performance (Lee and Burkam, 2009). However, at the same conference, Hannaway argued that moving produces consistently negative effects on mathematics scores and marginal effects on reading scores (Beatty, 2010).

According to Beatty (2010), housing problems are the main factor behind students' moves. Forty-three percent of households with children had at least one significant housing problem in 2007 (Beatty, 2010). These problems include housing that is physically inadequate or overcrowded, as well as housing that costs more than $30 \%$ of the resident's income. Persistent housing and poverty problems can motivate populations with children to move, which translates into high mobility rates. Forty-two percent of fourth-grade students from poor families changed schools in the last two years, compared with just $26 \%$ in non-poor families (Smith et al., 2008). A change in a family's physical residence - for whatever reason - is the main reason why students change schools (Beatty, 2010). 
Changing schools involves navigating a complex set of issues that span student learning, classroom instruction, and school organization (Kerbow, 1996). Student mobility not only affects the individual student who moves, but also affects the non-mobile children in the school. Evidence implies that when schools experience high rates of mobility, achievement levels decrease across the board. Lash and Kirpatrick (1990) state that high student mobility rates can also disrupt the learning environment in the classroom and throughout the school This suggests a negative spillover effect: the negative impacts of mobility reside in a school, even after the student has moved (Beatty, 2010). In other words, mobile students also influence the performance of non-mobile students. Student mobility is therefore likely to interfere with instruction, academic skills that build over time, and social networks.

Scholars reiterate that findings on mobility and performance are likely to be conservative (Beatty, 2010). The negative impacts of mobility are actually more pronounced than past studies have shown. Current researchers largely emphasize local studies over national studies to help examine the specific effects of mobility on student performance within a unique area. Thus, piecing together individual studies with robust findings can help shed more light on the dynamics of student mobility.

\section{Data Organization}

We utilized two data sets to calculate and interpret the effects of mobility. The first data set was obtained from Lane County Elections and contained the entire population of registered voters in Lane County in 2006 and 2008. This data set included around 400,000 observations and allows for the calculation of mobility rates with respect to age groups and geographical areas for the entire population of registered Lane County voters. Mobility rates were also calculated for the Promise Neighborhoods. It is acknowledged that this data set excludes those who are too young to vote - most of whom are the students and children United Way seeks to serve. However, this data set provides the most extensive information on address changes available. Since most children live with a parent or guardian, an adult moving may give insight into how frequently families move.

Our second data set included withdrawal codes for each student changing classrooms in the Bethel School District. While we focused on physical moves with the Lane County voter data set, we were uncertain whether a withdrawal from a school meant that a student had physically moved and changed addressed. Therefore, we used the Bethel data set to calculate measures of educational disruption. This variable served as a rough proxy for mobility.

\section{Lane County Election Data}

Using Lane County voter data, we were able to calculate the mobility rates of registered voters in Lane County. The data set included 394,577 observations across two years with names, precinct numbers, full addresses, and unique voter identification numbers. Using the unique voter identification numbers, we could match observations across the two time periods with very high accuracy. We then determined three possible categories for mobility for each 2006registered voter over the two-year period: 
1. Outbound Mobility: a registered voter had an observation in 2006 but no observation in 2008, and thus was presumed to have moved out of the county. Even if a citizen does not vote, that citizen remains in the data.

2. Churning: a registered voter had an observation in 2006 at a given address and an observation in 2008 at a different address.

3. No Move: a registered voter had an observation in 2006 and 2008 but at the same address.

The Lane County election data had a few yet important drawbacks that decreased the reliability of the estimates. First, there is a possibility that not every individual who moved in Lane County reregistered at his or her new address. Second, outbound mobility includes deaths. Registered voters who pass away are automatically removed from the database within two to three weeks after death. If an individual registered prior to the 2006 cutoff and died between 2006 and the 2008 cutoff, the individual is coded as outbound mobility. Our inability to distinguish between death and outbound mobility causes our calculation to have an upward bias. Conversely, individuals who have lower incomes are more mobile and are less likely to register to vote. According to U.S. Census data on elections and registration, there is a negative relationship between total family income decreases and the percentage of families registering to vote (Figure 3). Furthermore, there is a negative correlation between the duration of time spent in a household and the percentage of families registering to vote (Figure 4). This results in selection bias, causing the mobility rate calculations to be understated. We assert that this downward bias is likely far stronger that the upward bias resulting from voter death.



Figure 3. Family income and percent registered to vote in 2006, U.S. population. 




Figure 4. Duration of residence and percent registered to vote in 2006, U.S. population.

\section{Bethel School District Data}

We received data that coded each student withdrawal from a particular school in the Bethel School District from 2002-2008. Each code listed a specific reason for why the student left the classroom or school. We created four general groups for the withdrawal codes: private, public, out, and dropout. Observations with codes that did not fit into these categories were dropped from the data set, since they provided no ultimate insight into student mobility, and thus were outside the scope of our project.

1. PRIVATE: The student moved from a Bethel School to a private institution in the same area. Over the seven years of data, this code was never used.

2. PUBLIC: The student changed schools within the Bethel School District.

3. OUT: The student moved out of the Bethel School District.

4. DROPOUT: The student was not reported to be attending a new school, or the student simply had stopped attending for a variety of reasons, excluding reported health-related circumstances.

Unfortunately, problems with this data set forced us to transform the data set from an individual unbalanced panel (a data set where the number of years $(t)$ and the number of schools $(n)$ are unequal) into a school-wide balanced panel (a data set where $t$ and $n$ are equal). If the student withdrew from a school and was coded as a move within district, there was no new school code. Therefore, it was unclear where a student who moved within the district actually settled. We also lacked individual demographic information attached to individual students' moves. This would have been important to justify an argument for a direction of causality: 
particularly whether mobility affected test scores, or vice versa. Finally, the panel data set was very unbalanced: some students would have multiple observations in certain years and none in other years. With such a low number of total observations, we were concerned whether we would have enough degrees of freedom to pursue meaningful statistical results.

To organize the data into a balanced panel, each individual observation was grouped into school-wide percentages. For example, we determined the percentage of moves within the Bethel School district in school $i$ at time $t$. Oregon Department of Education statistics were then used to attach demographic information to each school in each respective period. The total number of students who exhibited the trait at a specific school (i) was divided by the total enrollment that specific year $(t)$. This produced a percent in terms of the entire student body. We included the variables:

$B L A C K_{i, t}:$ Percentage of students who self-identify as Black in school $i$ at time $t$.

$I_{N D I A N}{ }_{i, t}$ : Percentage of students who self-identify as Native American/Indian in school $i$ at time $t$.

$A S I A N_{i, t}$ : Percentage of students who self-identify as Asian in school $i$ at time $t$.

$H_{S P A N I C}$ : Percentage of students who self-identify as Hispanic in school $i$ at $t$.

$R A T I O_{i, t}$ : Ratio of students to teachers at school $i$ and time $t$.

$M E A N_{i, t}$ : Percentage of students who met or exceeded the state math benchmark at school $i$ at time $t$ added to the percentage of students who met or exceeded the state reading benchmark at school $i$ at time $t$ divided by two. This variable compiles math and reading scores, and acts as a proxy for average student performance.

$F R E E_{i, t}$ : Percentage of students who qualify for free lunch at school $i$ and time $t$.

We chose variables that would make it easy for United Way to target specific populations. For example, if we found that Black - or any other ethnicity - caused a decrease in student performance more than other variables, United Way could direct their resources towards a certain ethnicity. United Way could take this approach with other variables, such as students eligible for free lunch.

After preliminary analysis, Kalapuya High School, an alternative high school in the Bethel School District, was dropped from further analysis because its data contained a high number of outliers. Furthermore, we dropped the 2002 time period since not all schools had demographic data available in that year. After organization, the data were in the form of an unbalanced panel data set, with $t=6$ and $n=10$; thus, in total, there were 60 observations.

\section{Analysis}

The total mobility in Lane County had a maximum of $66 \%$ of individuals aged $24-26$ old, and a minimum of $20 \%$ in the 51-60 year-old age group. In the Promise Neighborhoods, mobility had a maximum of $65 \%$ in the $21-23$ year-old category, and a minimum of $24 \%$ in the $51-50$ year-old age group. 
In all of Lane County, the outbound mobility reached a maximum at $43 \%$ in the $21-23$ yearold age group, and a minimum of $10 \%$ in the 51-60 year-old age group. Outbound mobility in the Promise Neighborhoods reached a maximum at $42 \%$ in the 21-23 year-old age group, and a minimum of $12 \%$ in the $51-60$ year-old age group.

Mobility within Lane County peaked at 24\% in the 27-29 year-old age group, and dropped to a minimum of $8 \%$ in the $61+$ year-old age group. Mobility within the Promise Neighborhoods had a maximum of $28 \%$ in the $27-29$ year-old age group and a minimum of $9 \%$ for individuals over 61.

Figures 5 and 6 display mobility rates of registered voters in Lane County (Figure 5) and in the Promise Neighborhoods (Figure 6).

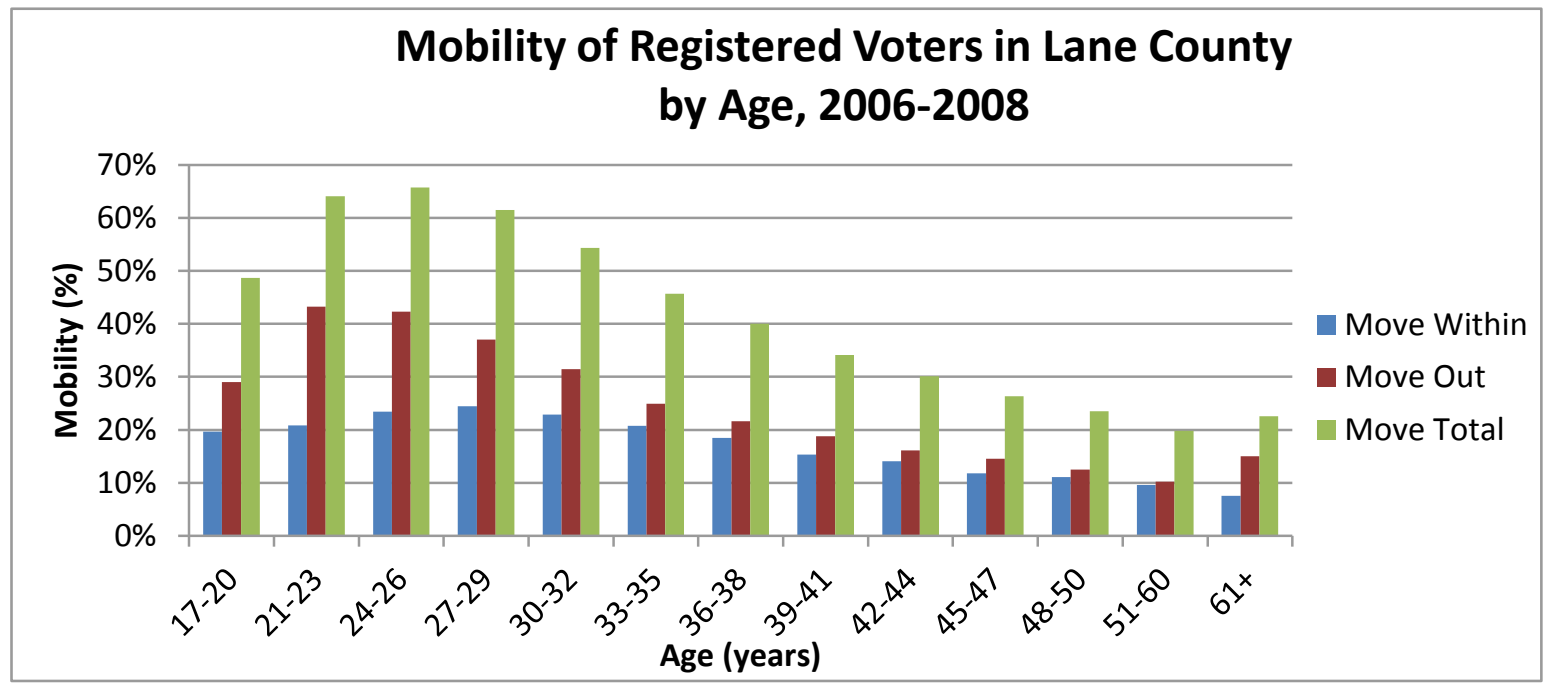

Figure 5. Mobility of registered voters in Lane County by age, 2006-2008.

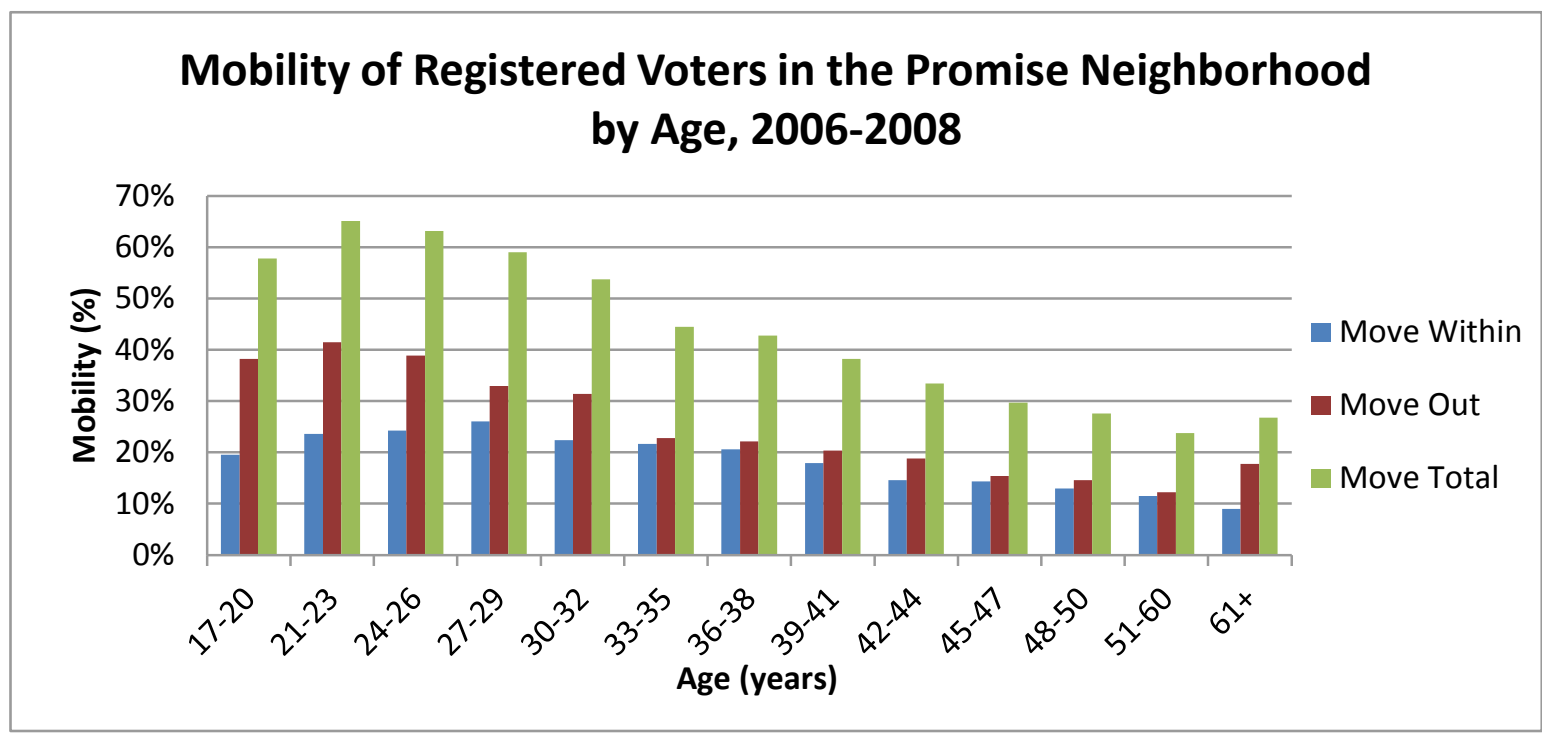

Figure 6. Mobility of registered voters in the Promise Neighborhood by age, 2006-2008. 
A multi-variable regression model was used to determine the effects of a list of explanatory variables on a dependent variable. This mathematical technique determines the effects of each explanatory variable and provides a unit-specific numerical estimate of how much that variable affects the dependent variable, controlling for other explanatory variables.

The ability to determine causality between mobility and student performance failed when data was transformed from individual to school-wide percentages. With demographic data attached to each individual who moved, it would have been possible to know which variables were having a unique effect on the dependent variable. Privacy concerns and time constraints kept us from acquiring this type of data. The variables included represent percentages across each school and year. Nonetheless, it is still possible to use the model to test the demographic variables' influence at the school-wide level.

The final two regressions (Tables 1 and 2) use mobility both as a dependent variable and as an explanatory variable. The first empirical model of the Bethel School District data used student performance as the dependent variable. The literature suggests that the casual relationship spanned from student mobility to student performance, and we wanted to explore whether this hypothesis was accurate in the Bethel School District. As noted in the background information, scholars disagree on whether mobility more strongly affects reading or math scores. Considering this disagreement, each school's reading and math test scores were averaged and used as the total performance variable. The second empirical model with the Bethel School District data instead used student mobility as the dependent variable in order to check the direction of causation.

Table 1: Regression model testing the hypothesis that average test scores influenced mobility within the district.

Dependent Variable: PUBLIC

\begin{tabular}{|c|c|c|c|c|}
\hline Variable & Coefficient & Std. Error & t-Statistic & Prob. \\
\hline $\mathrm{C}$ & 0.052877 & 0.021617 & 2.446122 & 0.0193 \\
\hline RATIO & 0.000127 & 0.000219 & 0.578006 & 0.5668 \\
\hline FREE & 0.008063 & 0.008310 & 0.970264 & 0.3382 \\
\hline BLACK & -0.072553 & 0.065588 & -1.106188 & 0.2758 \\
\hline HISPANIC & -0.003308 & 0.023157 & -0.142861 & 0.8872 \\
\hline ASIAN & -0.009165 & 0.039450 & -0.232314 & 0.8176 \\
\hline INDIAN & -0.063285 & 0.059769 & -1.058843 & 0.2965 \\
\hline MEAN & -0.130037 & 0.055853 & -2.328203 & 0.0255 \\
\hline SQMEAN & 0.078516 & 0.036695 & 2.139685 & 0.0390 \\
\hline \multicolumn{5}{|c|}{ Cross-section fixed (dummy variables) } \\
\hline \multicolumn{5}{|c|}{ Period fixed (dummy variables) } \\
\hline R-squared & 0.754803 & \multicolumn{2}{|c|}{ Mean dependent var } & 0.002202 \\
\hline Adjusted R-squared & 0.609010 & \multicolumn{2}{|c|}{ S.D. dependent var } & 0.004081 \\
\hline S.E. of regression & 0.002552 & \multicolumn{2}{|c|}{ Akaike info criterion } & -8.820988 \\
\hline Sum squared resid & 0.000241 & \multicolumn{2}{|c|}{ Schwarz criterion } & -8.018156 \\
\hline Log likelihood & 287.6296 & \multicolumn{2}{|c|}{ Hannan-Quinn criter. } & -8.506956 \\
\hline F-statistic & 5.177221 & \multicolumn{2}{|c|}{ Durbin-Watson stat } & 2233768 \\
\hline Prob(F-statistic) & 0.000006 & & & \\
\hline
\end{tabular}


Table 2: Regression model testing the hypothesis that moving within the district influenced average test scores

\begin{tabular}{cccrr} 
Dependent Variable: MEAN(1) & \multicolumn{1}{l}{} \\
\hline \hline Variable & Coefficient & Std. Error & t-Statistic & Prob. \\
\hline C & 0.736662 & 0.134980 & 5.457585 & 0.0000 \\
RATIO & 0.007377 & 0.005238 & 1.408427 & 0.1700 \\
FREE & -0.115141 & 0.146709 & -0.784828 & 0.4391 \\
BLACK & -3.068347 & 1.625216 & -1.887963 & 0.0694 \\
HISPANIC & 0.452954 & 0.587683 & 0.770745 & 0.4473 \\
ASIAN & 0.047676 & 1.193381 & 0.039950 & 0.9684 \\
INDIAN & -1.237077 & 1.241203 & -0.996676 & 0.3275 \\
PUBLIC(1) & -6.866180 & 3.005855 & -2.284268 & 0.0301 \\
PUBLIC & -6.953119 & 2.957995 & -2.350619 & 0.0260 \\
\hline \hline Cross-section fixed (dummy variables) & & & \\
Period fixed (dummy variables) & & & & \\
\hline \hline R-squared & & & & \\
Adjusted R-squared & 0.916583 & Mean dependent var & 0.769200 \\
S.E. of regression & 0.050598 & Akaike info criterion & -2.829610 \\
Sum squared resid & 0.071686 & Schwarz criterion & -1.988319 \\
Log likelihood & 92.74024 & Hannan-Quinn criter. & -2.509241 \\
F-statistic & 14.65066 & Durbin-Watson stat & 1.627852 \\
Prob(F-statistic) & 0.000000 & & & \\
\hline
\end{tabular}

For both models, linear least squares multi-variable regression with period and crosssectional fixed effects were used. Since the data was non-random, it was necessary to control for unobserved heterogeneity in the data when the heterogeneity was constant over time. Furthermore, it was necessary to control for differences in the data when anomalies were constant across schools. The fixed effects technique accomplishes both of these goals. In order to cope with heteroskedasticity, or unequal variance in the error terms, White's diagonal robust standard errors was used. This form is the most general technique, and robust to all forms of heteroskedasticity, especially when $N$ and $T$ are small and roughly the same size. To measure goodness of fit, R-squared was referenced and the Akaike Information Criterion was minimized. The significance of each explanatory variable was gauged at the $5 \%$ level.

Our first regression (Table 1) used $P U B L I C_{i, t}$ as the dependent variable and tested the hypothesis that average test scores influenced mobility within the district. We regressed all the demographic explanatory variables on $P U B L I C_{i, t}$. To investigate whether there was any nonlinear relationship, we also included a non-linear term, $S Q M E A N_{i, t}$ which was the square of the $M E A N_{i, t}$ variable. Apart from the constant, the only statistically significant variables $(\mathrm{p}<0.05)$ were $S Q M E A N_{i, t}$ and $M E A N_{i, t}$.

Our second regression (Table 2) used $M E A N_{i, t}$ as the dependent variable and tested the hypothesis that moving within the district influenced average test scores. We regressed all the demographic explanatory variables, including $P U B L I C_{i, t}$, on a dependent variable that was one period ahead: $M E A N_{i, t}(+1)$. This was done to determine whether mobility $\left(P U B L I C_{i, t}\right)$ or any of 
the other explanatory variables had an effect on mean test scores starting in the next school year. We also included a contemporaneous $P U B L I C_{i, t}(+1)$ to determine if mobility had an effect on mean test scores in the same period. Apart from the constant, the only statistically significant variables $(\mathrm{p}<0.05)$ were PUBLIC $_{i, t}$ and $P U B L I C_{i, t}(+1)$.

\section{Results}

Several mobility trends are present in both the Promise Neighborhoods and in Lane County. We observed high rates of outbound mobility in younger age demographics, with that trend decreasing steadily after age 30. Additionally, outbound mobility reaches its maximum at 21-23, whereas mobility within reaches its maximum in the 27-29 year old age group. This data suggest that young parents, in age groups anywhere between 20-30 years old, may move more frequently than older parents.

The first regression showed that, across all schools and periods, a school's average test scores had a significant effect on the same school's mobility rate. This linear relationship was negative; a $1 \%$ increase in a school's average test scores was associated with a $0.13 \%$ decrease in the same school's mobility rate. However, this non-linear relationship was positive; a $1 \%$ increase in the square of a school's average test scores was associated with a $0.07 \%$ increase in the same school's mobility rate.

Figure 7 contains a graph representing the change in average test scores, holding all other variables in the regression constant.

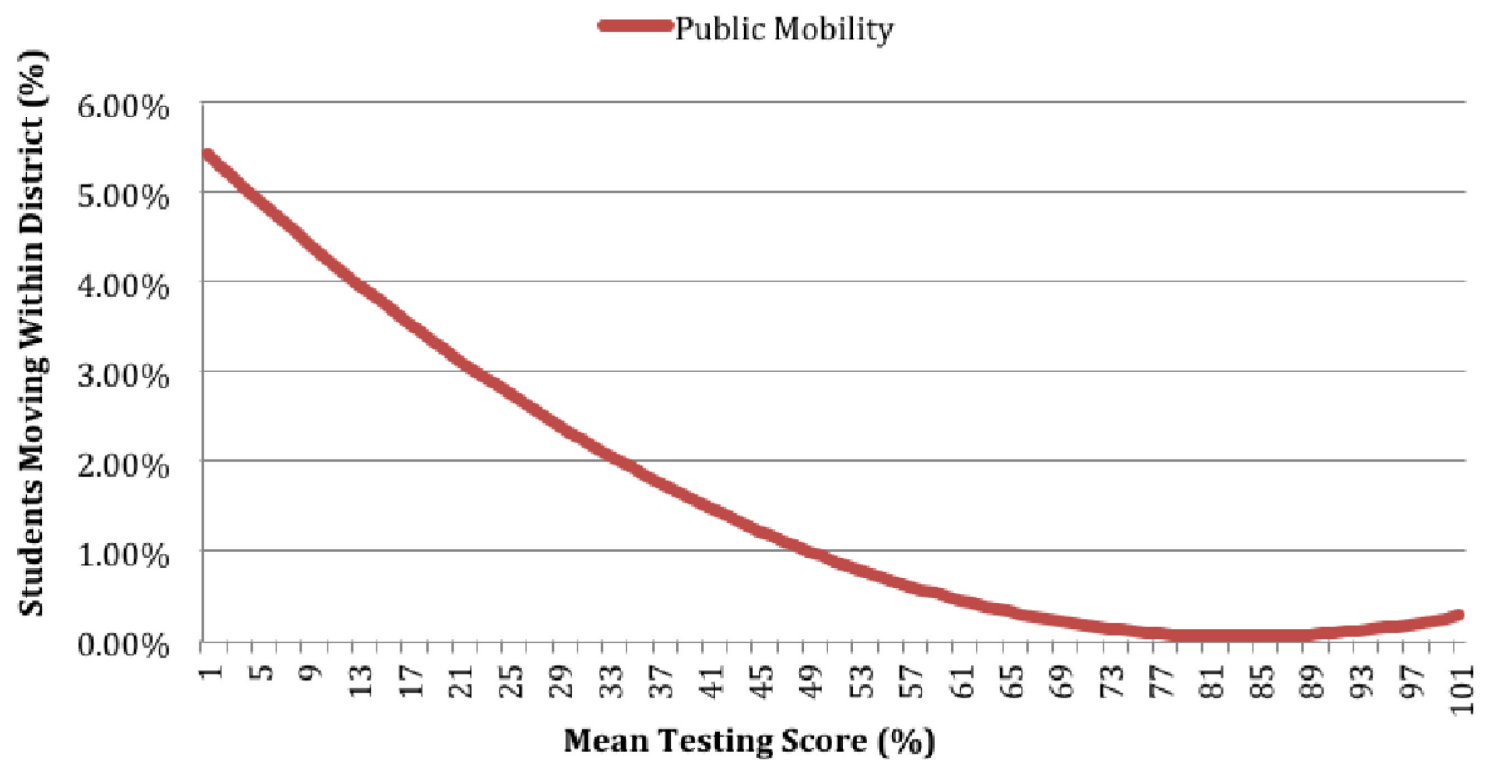

Figure 7. Estimated mobility within Bethel School District.

The negative slope of the line indicates that there is a negative relationship between a school's average test scores and its mobility rate. Furthermore, this relationship exhibits decreasing marginal returns, meaning the curve's slope decreases as average test scores increase. In other words, a percentage change in average test scores is associated with a 
decreasing percentage change on the mobility rate as average test scores increase. At a low mean test score, mobility will change more; at a high mean test score, mobility will change less. Hypothetically, if United Way were to spend money to increase test scores with the hope of decreasing the percentage of student moving within the Bethel School District, it would get the most effective use of its recourses by targeting schools with lower average test scores. That said, it cannot be implied that average test scores influences mobility, but rather that the relationship between test scores and mobility exhibits decreasingly marginal returns.

The second regression found that, across all schools and periods, mobility had a detrimental effect on a school's average test scores. Considering the lagged $P U B L I C_{i, t}$, the previous period's mobility rate turned out to have a negative effect on student performance in the following period. A $1 \%$ change in the percentage of students moving within the district in one year at a particular school is associated with a $6.95 \%$ decrease in average test scores the following year at the same school. Looking at the contemporaneous variable, PUBLIC $i, t+1)$, moving in the same period had a negative effect on student performance in the same period. A 1\% change in the percentage of students moving within the district in one year at a particular school is associated with a $6.86 \%$ decrease in average test scores in the same year at the same school. The coefficient values are very similar (-6.95 versus -6.86$)$, suggesting the residual effects of student mobility are closely related to the contemporaneous effects of mobility at the same school.

Due to the generalization of our data, it can only be inferred that mobility, though significant in both regression models, is only a powerful negative relationship. In the first model, it was estimated that average student performance in a certain school has a negative effect on mobility, with the relationship exhibiting decreasing marginal returns. In the second model, it was estimated that student mobility has a negative effect on average student performance in a school, both in the previous period and the contemporaneous period. Both of the models show that there is a strong negative relationship between mobility and student performance. However, the panel data that was used in the regressions were school-wide averages instead of individual observations; therefore, it cannot be concluded that either the act of a student moving causes a decrease of test scores, or that low test scores will cause one to move. It is not known if the students who moved belonged to a certain ethnicity, income level, or had low or high state test scores. Furthermore, if a student moved, we did not know where the student physically moved.

A perfect data set would include a data point for each mobile student, indicating his or her specific demographic data. It would also include that individual's state testing scores. Analysts would also need to code which school the student left, and where in the district a student moved.

\section{Conclusions}

The pure effects of mobility and student performance cannot be determined and it was concluded that mobility was merely a signal. The study found that schools with a higher percentage of mobile students have lower average test scores, but it is not known, demographically, what kind of students these mobile students are. Furthermore, we do not know for certain why a school's average student performance decreases. The following are a few 
hypotheses that might explain the findings surrounding the relationship between mobility and student performance

- High-performing students are moving out of a school, lowering the school's average test scores.

- Spillover effects: mobile students are negatively affecting non-mobile students' performance at school.

- Low-performing students move to a new school, causing the new school's average to decrease faster than increases in student performance.

Overall, a school's mobility rate signals that either mobile students - or possibly an unobserved demographic group that our data could not measure within the mobile population need attention. The results suggest that, in the Bethel School District, there is a negative relationship between a school's mobility rate and the respective school's average student performance. United Way must address mobile populations, as the results show they are associated with lower student performance. Although the causal relationship will require further research, we conclude that mobility should be measured and explored to maximize outcomes generated by United Way's Promise Neighborhoods program.

\section{Acknowledgements}

We would like to thank our advisor, Professor Joe Stone and our primary contact with United Way, Holly Mar Conte. Additionally, we thank Drew Braun, Glen Waddell, Bill Harbaugh, Bruce Blonigen, Lane County Elections, and Kim Breeding.

\section{Works Cited}

Beatty, Alexandra, comp. (2010). Student Mobility: Exploring the Impact of Frequent Moves on Achievement: Summary of a Workshop. National Research Council and Institute of Medicine.

Kerbow, David. (1996). Patterns of Urban Student Mobility and Local School Reform. Center for Research on the Education of Students Placed at Risk 5 .

Lash, A.A., and Kirkpatrick, S.L. (1990). A classroom perspective on student mobility. Elementary School Journal, 91(2), 177-191.

Mar Conte, Holly. Personal Interview. 13 May 2011.

Smith, Jean Louise M., Fien, Hank, and Paine, Stan C. (2008). When Mobility Disrupts Learning. Educational Leadership, 65.

United Way. Lane County Promise Neighborhoods. $10 \quad$ June 2011. <http://www.unitedwaylane.org/what-we-do/community-impact/education/success-by6/promise-neighborhoods/> 